\title{
Time trend of axial length and associated factors in 4- and 5- year-old children in Shanghai from 2013 to 2019
}

\author{
Tao Li $\cdot$ Ting Wan $\cdot$ Xiaoqian Yao $\cdot$ Huihong Qi $\cdot$ Xuefeng Chen • \\ Man She $\cdot$ Qianqian $\mathrm{Hu} \cdot$ Xiaodong Zhou
}

Received: 13 February 2020/Accepted: 29 October 2020/Published online: 12 November 2020

(C) The Author(s) 2020

\begin{abstract}
Purpose To evaluate the time trend of axial length (AL) and associated factors in 4- and 5-year-old children in Shanghai from 2013 to 2019.

Methods This was a 7-year observational study of 985 four-year-old and 1059 five-year-old children in Shanghai. AL, horizontal and vertical corneal curvature, spherical equivalent (SE), and body height and weight were measured. Furthermore, a questionnaire
\end{abstract}

T. Li · T. Wan · X. Yao - M. She $\cdot$ Q. Hu $\cdot$ X. Zhou $(\bowtie)$ Department of Ophthalmology, Jinshan Hospital of Fudan University, 1508 Longhang Road, Shanghai 201508,

China

e-mail: xdzhou_2013@163.com

T. Li

e-mail: litao13013@sina.com

T. Wan

e-mail:wanwan0796@126.com

X. Yao

e-mail: xqyao0709@163.com

M. She

e-mail: sheman11@163.com

Q. $\mathrm{Hu}$

e-mail: 18211270007@fudan.edu.cn

T. Li

Department of Ophthalmology, Eye and ENT Hospital of Fudan University, Shanghai, China was collected, including time outdoors and bad eyesight habits.

Results In 4-year-old children, no significant difference was found in $\mathrm{AL}(P=0.526)$, but significant differences were observed in SE $(P=0.001)$, horizontal corneal curvature $(P=0.006)$, vertical corneal curvature $(P=0.004)$, height $(P<0.001)$, and weight $(P=0.022)$ from 2013 to 2019. In 5-year-old children, no significant differences were found in $\mathrm{AL}$ $(P=0.304)$, SE $(P=0.200)$, or weight $(P=0.292)$,

H. Qi · X. Chen · X. Zhou Center of Eye Disease Prevention, Jinshan District, Shanghai, China

e-mail: 466983910@qq.com

X. Chen

e-mail: xfchen33@126.com 
but significant differences were observed in horizontal corneal curvature $(P=0.040)$, vertical corneal curvature $(P=0.015)$, and height $(P<0.001)$ from 2013 to 2019. Multivariate analyses revealed that AL was mainly significantly associated with boys and time outdoors in the 4- and 5-year-old children.

Conclusions The AL of 4- and 5-year-old children remained relatively stable in Shanghai from 2013 to 2019. Longitudinal studies are needed to confirm the relationship between AL elongation and environmental risk factors.

Keywords Axial length · Preschool-age children · Time trend $\cdot$ Associated factors

\section{Introduction}

Myopia, which is the result of a mismatch between the axial length (AL) and ocular refractive power, has become a major public health issue worldwide [1]. AL is thus an important anatomic parameter for the optics of the eye, determining the refraction. Furthermore, the AL may be the primary factor for the eventual development of myopia-related visual impairment complications, such as retinal detachment, optic disc abnormalities, myopic macular degeneration, and choroidal neovascularization [2-4]. The risk of visual impairment is highest for those with high myopia, especially when having an AL above $30 \mathrm{~mm}$ [5]. Therefore, AL may be a principal determinant of ocular function.

Vision screening is recommended at least once in all children aged 3-5 years old by the US Preventive Services Task Force [6]. Despite the importance of AL, few population-based studies have focused on $\mathrm{AL}$, especially in preschool children [7-12]. The purpose of this study is to evaluate the time trend of AL in 4- and 5-year-old children, and to assess potential factors associated with AL in these children in a kindergarten in Shanghai from 2013 to 2019.

\section{Methods}

Subjects

This was a 7-year observational study in Jinshan District in the southwest of Shanghai, China. Children aged 4 or 5 years from one kindergarten were included in the study, including 985 four-year-olds and 1059 five-year-olds. The exclusion criteria were history of severe ocular diseases (e.g., cataract, glaucoma, strabismus, and amblyopia) and surgeries.

The study was approved by the Ethics Committee of Jinshan Hospital of Fudan University, China. All study procedures adhered to the tenets of the Declaration of Helsinki. Written informed consent was obtained from the parents or guardians of all children.

\section{Examination}

The annual visit was completed between 1 September and 31 December from 2013 to 2019, except for 2015, when no ocular examination was carried out for kindergarten children. An ocular biometry system (IOL Master; Carl Zeiss Meditec, Oberkochen, Germany) was used to obtain the axial length (AL), and horizontal and vertical corneal curvature. The mean value of five good measurements was used in the analysis. According to our previous studies [13, 14], an auto-refractor (RK-F1; Canon Corporation, Tokyo, Japan) was used to measure refraction under noncycloplegic conditions. The mean value of three good measurements was used in the analysis.

Furthermore, body height and weight were recorded for all children, measured in a standard manner without shoes or thick clothes.

In addition, a questionnaire regarding daily life activities was completed by the child's parents or guardians when the child started school every September. Time spent outdoors was obtained using questions such as "How much time does your child spend outdoors every day?" separately for weekdays and weekend days. The mean number of hours per day was calculated as time spent during weekdays $\times 5 /$ $7+$ time spent on weekend days $\times 2 / 7$. Furthermore, dichotomous variables (coded 1 or 0 ) were also recorded, including gender $(1=$ boy, $0=$ girl $)$ and bad eyesight habits, such as continuously reading books, writing homework, or playing with electronic devices for $30-40 \mathrm{~min}(1=$ none, $0=$ frequent or 
sometimes), excessive bending, suggesting a distance between the eye and desk of less than $33 \mathrm{~cm}$ ( $1=$ none, $0=$ frequent or sometimes), watching TV from a distance of less than $2 \mathrm{~m}(1=$ none, $0=$ frequent or sometimes), and wrong sitting posture, suggesting a distance between the thorax and desk of less than the size of a fist $(1=$ none, $0=$ frequent or sometimes).

\section{Statistical analysis}

Both eyes of each child were examined, but only data from the right eye was used for the analysis. Spherical equivalent (SE) was calculated as spherical power + 0.5 negative cylinder power. According to previous studies [13, 15], myopia was defined as $\mathrm{SE} \leq-1.00$ $\mathrm{D}$, emmetropia as $-1.00 \mathrm{D}<\mathrm{SE}<+2.00 \mathrm{D}$, and hyperopia as $\mathrm{SE} \geq+2.00 \mathrm{D}$.

SPSS V.17.0 software was used for data analysis. One-way analysis of variance with the Bonferroni post hoc test was used to analyze the differences of covariates for 4- and 5-year-old children from 2013 to 2019. Independent $t$-test was used to analyze the differences of $\mathrm{AL}$ and $\mathrm{SE}$ between all the 4- and 5-year-old children. Multivariate linear regression analysis was performed to assess the potential associated factors for AL. All $p$ values were two-sided and considered statistically significant when less than 0.05 .

\section{Results}

As shown in Fig. 1a, for the 4-year-olds, there were 187 including $77(41.2 \%)$ girls in 2013, 157 children including $72(45.9 \%)$ girls in 2014, 186 children including $77(48.4 \%)$ girls in 2016, 165 children including $88(53.3 \%)$ girls in 2017, 129 children including $60(46.5 \%)$ girls in 2018, and 161 children including $73(45.3 \%)$ girls in 2019. As shown in Fig. 1b, for the 5-year-olds, there were 195 children including $74(37.9 \%)$ girls in 2013, 188 children including $83(44.1 \%)$ girls in 2014, 166 children including $81(48.8 \%)$ girls in 2016, 201 children including $98(48.8 \%)$ girls in 2017, 161 children including $81(50.3 \%)$ girls in 2018, and 148 children including $70(47.3 \%)$ girls in 2019.

The mean AL of the 4- and 5-year-old children was $22.21 \pm 0.69 \mathrm{~mm}$ and $22.45 \pm 0.70 \mathrm{~mm}$, respectively, with significant difference $(P<0.001)$ from
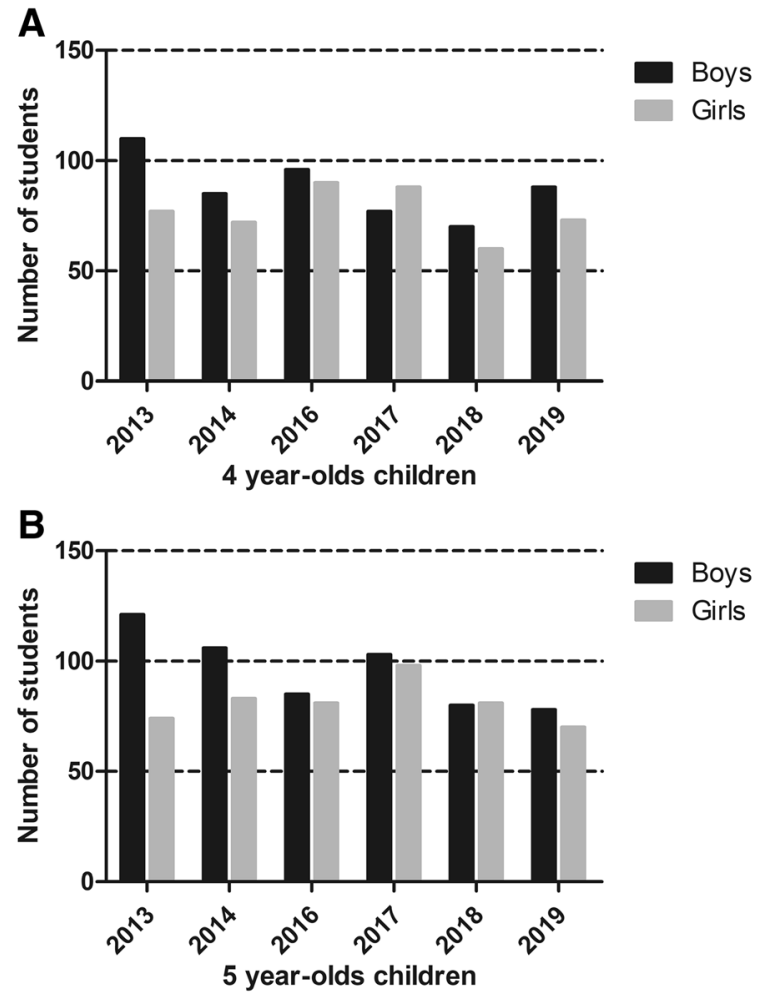

Fig. 1 Number of 4- and 5-year-old children

2013 to 2019. The most common AL range was 22-23 mm in the 4-year-old children (Fig. 2a; $48.1 \%$ in $2013,49.7 \%$ in $2014,56.3 \%$ in $2016,50.9 \%$ in $2017,48.5 \%$ in 2018 , and $53.1 \%$ in 2019) and 5-yearold children (Fig. 2b; 54.4\% in 2013, 52.4\% in 2014, $51.2 \%$ in $2016,54.5 \%$ in $2017,53.4 \%$ in 2018 , and $47.3 \%$ in 2019). The mean SE of the 4- and 5-year-old children was $0.03 \pm 1.73 \mathrm{D}$ and $0.06 \pm 1.30 \mathrm{D}$, respectively, without significant difference ( $P=0.700)$ from 2013 to 2019 . The most common refraction was emmetropia in 4-year-old children (Fig. 3a; $93.6 \%$ in 2013, 93.6\% in 2014, 88.2\% in $2016,84.8 \%$ in $2017,81.4 \%$ in 2018 , and $90.1 \%$ in 2019) and 5-year-old children (Fig. 3b; $90.8 \%$ in $2013,94.7 \%$ in $2014,87.3 \%$ in $2016,88.6 \%$ in 2017 , $86.3 \%$ in 2018, and $87.2 \%$ in 2019).

As shown in Table 1, no significant difference was found in $\mathrm{AL}(P=0.526)$ in 4-year-old children from 2013 to 2019, whereas significant differences were observed in SE $(P=0.001)$, horizontal corneal curvature $(P=0.006)$, vertical corneal curvature $(P=0.004), \quad$ height $\quad(P<0.001), \quad$ and weight $(P=0.022)$ from 2013 to 2019 . Bonferroni post hoc 


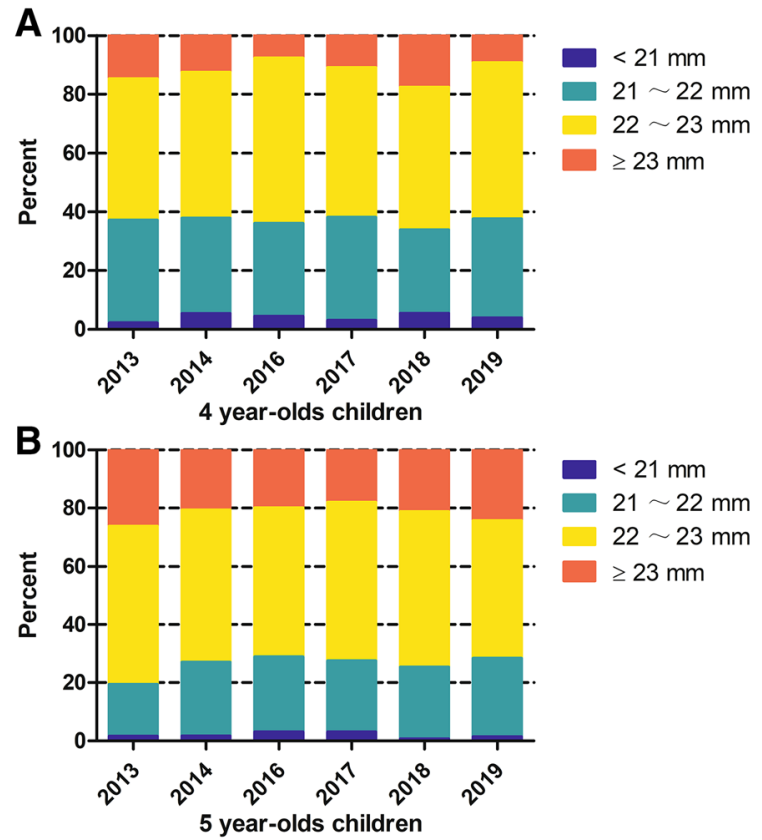

Fig. 2 Percentages of different axial length of 4- and 5-year-old children

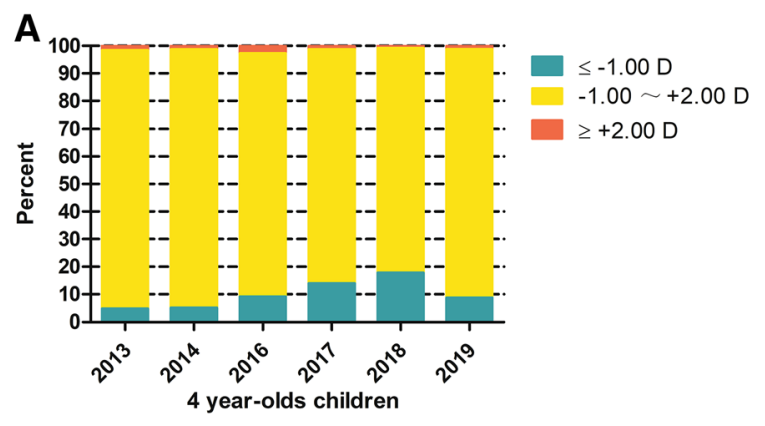

B

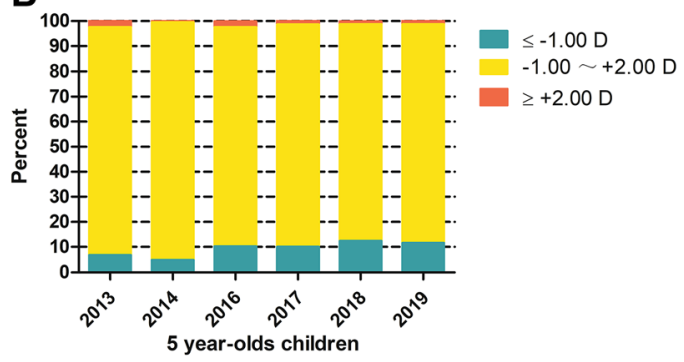

Fig. 3 Percentages of different spherical equivalent of 4- and 5-year-old children

tests further showed that SE was higher in 2013 than in 2017, 2018, and 2019 (all $P<0.05$ ). Horizontal and vertical corneal curvature were smaller in 2013 than in 2016 ( $P=0.002$ and $P=0.002$, respectively). Height was lower in 2013 than in 2014, 2017, 2018, and 2019 (all $P<0.05$ ), greater in 2014 than in 2016, 2017, 2018, and 2019 (all $P<0.05$ ), and lower in 2016 than in $2018(P=0.016)$. Although there was a significant difference in weight $(P=0.022)$ from 2013 to 2019, no significant differences were observed in paired comparisons (all $P>0.05$ ). As shown in Table 2, no significant differences were found in $\operatorname{AL}(P=0.304)$, SE $(P=0.200)$, or weight $(P=0.292)$ in 5-year-old children from 2013 to 2019, whereas significant differences were observed in horizontal corneal curvature $(P=0.040)$, vertical corneal curvature $(P=0.015)$, and height $(P<0.001)$ from 2013 to 2019. Bonferroni post hoc tests further showed that vertical corneal curvature was smaller in 2013 than in 2017 ( $P=0.016)$, whereas horizontal corneal curvature was marginally smaller than in $2017(P=0.050)$. Height was lower in 2013 than in 2014, 2017, 2018, and 2019 (all $\mathrm{P}<0.05$ ), but greater in 2014 than in 2016, 2017, and 2018 (all $P<0.05$ ).

As shown in Table 3, for the 4-year-old children, multivariate analysis revealed that $\mathrm{AL}$ was significantly associated with boys $(P<0.001)$ in 2013 , with time outdoors $(P<0.001)$ in 2014 , with time outdoors $(P<0.001)$ in 2016 , with boys $(P<0.001)$ in 2017 , with boys $(P<0.001)$ in 2018 , and with boys $(P<0.001)$ in 2019. As shown in Table 4 , for 5-year-old children, multivariate analysis revealed that $\mathrm{AL}$ was significantly associated with boys $(P<0.001)$ and time outdoors $(P=0.048)$ in 2013, with time outdoors $(P<0.001)$ in 2014 , with time outdoors $(P<0.001)$ and continuously using eyes for 30-40 min $(P=0.018)$ in 2016, with boys $(P=0.001)$ in 2017 , with boys $(P<0.001)$ and time outdoors $(P=0.018)$ in 2018 , and with boys $(P=0.023)$ in 2019 .

\section{Discussion}

In the present study, the most common AL range was $22-23 \mathrm{~mm}$ and the most common refraction was emmetropia in 4- and 5-year-old children from 2013 to 2019, except for 2015. There were no significant increases of AL in 4- or 5-year-old children in Shanghai from 2013 to 2019. However, AL was mainly significantly associated with boys and time 
Table 1 Demographic characteristics of 4-year-old children

\begin{tabular}{|c|c|c|c|c|c|c|c|}
\hline & 2013 & 2014 & 2016 & 2017 & 2018 & 2019 & $P$ \\
\hline Axial length (mm) & $22.24 \pm 0.70$ & $22.18 \pm 0.72$ & $22.16 \pm 0.66$ & $22.21 \pm 0.64$ & $22.30 \pm 0.72$ & $22.19 \pm 0.72$ & 0.526 \\
\hline $\begin{array}{l}\text { Spherical equivalent } \\
\text { (D) }\end{array}$ & $0.49 \pm 3.15$ & $0.11 \pm 0.75$ & $-0.01 \pm 1.22$ & $-0.17 \pm 1.09$ & $-0.31 \pm 1.77$ & $-0.07 \pm 1.82$ & 0.001 \\
\hline $\begin{array}{l}\text { Horizontal corneal } \\
\text { curvature (D) }\end{array}$ & $42.22 \pm 3.78$ & $42.71 \pm 1.37$ & $42.10 \pm 6.58$ & $42.78 \pm 1.45$ & $42.49 \pm 1.62$ & $42.75 \pm 1.27$ & 0.006 \\
\hline $\begin{array}{l}\text { Vertical corneal } \\
\text { curvature (D) }\end{array}$ & $43.32 \pm 3.91$ & $43.84 \pm 1.47$ & $43.23 \pm 6.75$ & $43.90 \pm 1.61$ & $43.58 \pm 1.78$ & $43.96 \pm 1.46$ & 0.004 \\
\hline Height (cm) & $105.8 \pm 4.9$ & $113.9 \pm 7.5$ & $107.2 \pm 9.0$ & $107.9 \pm 4.4$ & $109.5 \pm 5.1$ & $108.2 \pm 4.9$ & $<0.001$ \\
\hline Weight (kg) & $18.0 \pm 9.9$ & $19.2 \pm 3.9$ & $18.4 \pm 5.2$ & $17.9 \pm 2.4$ & $19.7 \pm 2.9$ & $18.2 \pm 8.2$ & 0.022 \\
\hline
\end{tabular}

Table 2 Demographic characteristics of 5-year-old children

\begin{tabular}{|c|c|c|c|c|c|c|c|}
\hline & 2013 & 2014 & 2016 & 2017 & 2018 & 2019 & $P$ \\
\hline Axial length (mm) & $22.51 \pm 0.67$ & $22.43 \pm 0.67$ & $22.40 \pm 0.79$ & $22.35 \pm 0.70$ & $22.46 \pm 0.67$ & $22.46 \pm 0.72$ & 0.304 \\
\hline Spherical equivalent (D) & $0.26 \pm 2.30$ & $0.06 \pm 0.66$ & $0.03 \pm 1.03$ & $0.03 \pm 0.99$ & $0.01 \pm 0.89$ & $-0.10 \pm 1.01$ & 0.200 \\
\hline $\begin{array}{l}\text { Horizontal corneal } \\
\text { curvature (D) }\end{array}$ & $42.17 \pm 2.84$ & $42.49 \pm 3.51$ & $42.74 \pm 1.37$ & $42.83 \pm 1.42$ & $42.76 \pm 1.44$ & $42.69 \pm 1.41$ & 0.040 \\
\hline $\begin{array}{l}\text { Vertical corneal } \\
\text { curvature (D) }\end{array}$ & $43.29 \pm 2.92$ & $43.53 \pm 3.63$ & $43.81 \pm 1.37$ & $44.06 \pm 1.53$ & $43.81 \pm 1.58$ & $43.95 \pm 1.64$ & 0.015 \\
\hline Height (cm) & $112.7 \pm 5.4$ & $116.9 \pm 5.6$ & $114.2 \pm 5.6$ & $114.6 \pm 4.6$ & $114.7 \pm 4.8$ & $115.4 \pm 4.4$ & $<0.001$ \\
\hline Weight (kg) & $20.3 \pm 7.9$ & $21.2 \pm 3.8$ & $21.2 \pm 5.5$ & $21.0 \pm 3.9$ & $21.3 \pm 3.1$ & $21.4 \pm 3.6$ & 0.292 \\
\hline
\end{tabular}

outdoors in the 4- and 5-year-old children, respectively. These results may be helpful for understanding the changing trend of $\mathrm{AL}$ and increasing prevalence of myopia in the younger generation of China.

In this study, the mean AL of 4- and 5-year-old children in Jinshan District was $22.21 \pm 0.69 \mathrm{~mm}$ and $22.45 \pm 0.70 \mathrm{~mm}$, respectively, in agreement with previous studies carried out in Shanghai $[8,9]$. Zhang et al. [8] found that the mean AL of 4- and 5-year-old children in Jiading and Xuhui District in 2013 was $22.18 \pm 0.69 \mathrm{~mm}$ and $22.47 \pm 0.71 \mathrm{~mm}$, respectively, with significant difference between genders. He et al. [9] found that the mean AL of 4- and 5-yearold children in Jiading District in 2017 was $22.16 \pm 0.65 \mathrm{~mm}$ and $22.32 \pm 0.71 \mathrm{~mm}$, respectively. Furthermore, the mean $\mathrm{AL}$ of 4-5-year-old children was reported to be $22.30 \mathrm{~mm}$ in Nanjing in 2016 [12], and $22.04 \pm 0.68 \mathrm{~mm}$ in the USA [10]. In addition, the mean AL of 3-4-year-old children was $22.10 \pm 0.79 \mathrm{~mm}$ in Pudong New District, Shanghai in 2017 [11], and the mean AL of 2-7-year-old children was $22.04 \pm 0.92 \mathrm{~mm}$ in Korea from 1988 to 1989 [7]. The mean AL of 3-year-old children was calculated to be $22.07 \mathrm{~mm}$ according to an established algorithm in Denmark in 1996 [16]. When comparing the AL among different studies, differences in age and AL measurement technique should be noted. Firstly, AL increases with age in children [10], suggesting that a wider age range will have an obvious effect on $\mathrm{AL}$ comparisons. Secondly, different AL measurement methods may also play an important role, such as IOL Master [8, 9, 11], an immersion A-scan sonogram $[7,10]$, or calculation [16]. In this study, the AL was measured using the IOL Master. The values obtained from the IOL Master would be larger than those obtained from an immersion A-scan sonogram 
theoretically, because the former measures the distance between the anterior surface of the tear film and the pigment epithelial without contact, whereas the ultrasonic measuring instrument measures the distance between the anterior surface of the cornea and the vitreous boundary membrane with contact. To the best of the authors' knowledge, we first reported no significant AL changing trend over the last 7 years from 2013 to 2019. Lin et al. [17] found that the mean prevalence of myopia among 7-year-olds increased from $5.8 \%$ in 1983 to $21 \%$ in 2000 . Holden et al. [18] estimated that the prevalence of myopia would increase from $23 \%$ in 2000 to $50 \%$ in 2050 . We suggest that the prevalence of myopia in preschool children may not have increased from 2013 to 2019 due to the relative stability of AL. Rapid increases of $\mathrm{AL}$ and prevalence of myopia may occur in school-age children due to changes in social environmental risk factors such as aggravation of learning tasks, extension of learning time, additional after-school tutoring classes, etc.

In this study, parameters including horizontal corneal curvature, vertical corneal curvature, and height in both 4- and 5-year-old children and weight in 5-year-old children were significantly different from 2013 to 2019; however, few significant differences were observed in paired comparisons. Jiang et al. [19] found that flatter horizontal corneal curvature was significantly associated with larger corneal diameter in 4-18-year-old children, which was significantly associated with taller body height but not correlated with time outdoors. Furthermore, an abnormally large cornea $(2.6 \%)$ and an abnormally small cornea $(2.4 \%)$ [19] were not classified or interpreted in this study but may influence the mean value of corneal curvature. In addition, corneal curvature was also influenced by birth weight and gestational age [20-22]. Birth weight was negatively correlated with horizontal/vertical corneal curvature [20, 23]. Children's height was significantly positively associated with boys, higher maternal height, higher maternal education levels, higher family income, and higher percentage of energy intake from protein [24]. Children's weight was associated with eating rate and degree of chewing [25] and parental feeding practices [26]. This study did not collect and analyze these factors, but they may partly explain the differences between paired comparisons. Further study including these factors should be conducted. 
Table 4 Multivariate linear regression analysis for potential factors associated with axial length in 5-year-old children

\begin{tabular}{|c|c|c|c|c|c|c|c|c|c|c|c|c|}
\hline & \multicolumn{2}{|l|}{2013} & \multicolumn{2}{|l|}{2014} & \multicolumn{2}{|l|}{2016} & \multicolumn{2}{|l|}{2017} & \multicolumn{2}{|l|}{2018} & \multicolumn{2}{|l|}{2019} \\
\hline & $B$ & $P$ & $B$ & $P$ & $B$ & $P$ & $B$ & $P$ & $B$ & $P$ & $B$ & $P$ \\
\hline Gender & 0.348 & $<0.001$ & -0.031 & 0.314 & 0.323 & $<0.001$ & 0.264 & 0.001 & 0.414 & $<0.001$ & 0.196 & 0.023 \\
\hline $\begin{array}{l}\text { Time } \\
\text { outdoors }\end{array}$ & -0.134 & 0.048 & 0.936 & $<0.001$ & 0.059 & 0.436 & 0.020 & 0.787 & -0.183 & 0.018 & -0.040 & 0.635 \\
\hline $\begin{array}{l}\text { Bad habit } \\
1\end{array}$ & -0.015 & 0.822 & 0.018 & 0.589 & 0.179 & 0.018 & -0.076 & 0.313 & 0.124 & 0.112 & -0.023 & 0.794 \\
\hline $\begin{array}{l}\text { Bad habit } \\
2\end{array}$ & -0.025 & 0.714 & -0.013 & 0.713 & -0.036 & 0.660 & -0.006 & 0.936 & -0.061 & 0.460 & -0.015 & 0.873 \\
\hline $\begin{array}{l}\text { Bad habit } \\
3\end{array}$ & -0.082 & 0.235 & 0.010 & 0.751 & -0.024 & 0.773 & 0.055 & 0.470 & -0.023 & 0.785 & 0.073 & 0.440 \\
\hline $\begin{array}{l}\text { Bad habit } \\
4\end{array}$ & -0.112 & 0.110 & 0.031 & 0.390 & 0.060 & 0.437 & -0.066 & 0.383 & 0.074 & 0.350 & 0.058 & 0.536 \\
\hline
\end{tabular}

Bad habit 1: Continuously using eyes for reading books, writing homework, or playing with electronic devices for 30-40 min; Bad habit 2: Excessive bending; Bad habit 3: Distance of less than $2 \mathrm{~m}$ when watching TV; Bad habit 4: Wrong sitting posture

Interestingly, our study found that AL was positively associated with time outdoors. Numerous studies have shown a protective effect of outdoor activities on myopia onset [27-31]. Addition of $40 \mathrm{~min}$ [27] or $80 \mathrm{~min}$ [31] of outdoor activity each day could reduce the incidence rate of myopia among primary-schoolage children in China. Wu et al. [29] found that time outdoors of more than $11 \mathrm{~h}$ could lead to significantly less myopic shift and AL elongation. Deng et al. [32] found an overall protective effect against axial elongation from outdoor activities, albeit with a small and clinically nonsignificant overall treatment effect. The mechanism is generally accepted to be that sunlightinduced release of retinal dopamine could inhibit eyeball elongation [1,33]. Therefore, besides time spent outdoors, outdoor lighting quality should also receive attention. This was just an observational study of AL in children from 2013 to 2019, and the relationship between AL elongation and outdoor activity time should be confirmed by longitudinal studies.

The present observational study suggested that AL was not associated with bad eyesight habits. Previous studies have shown that computer/Internet use was not related to incident myopia [34], and time and distance of near-work activity were not related to myopia progression [35], while protective behaviors related to close work (e.g., discontinuing close work every
30 min, longer distance in close work) could decrease myopia prevalence and reduce its progression [30]. But these studies did not measure AL. However, Ding et al. [36] found that longer near-work time was a risk factor for longer AL. Furthermore, Morgan et al. [37] suggested that intense schooling was linked to myopia, playing a major role in the current epidemic of myopia.

There may be some limitations to this study. Firstly, AL was analyzed in only one kindergarten with small sample size, which may not be representative of the whole of Shanghai. Secondly, refraction was determined by non-cycloplegic autorefraction, which may result in misclassification of refractive error, with an overestimation of myopia and underestimation of hyperopia. A difference of approximately $0.87 \mathrm{D}$ was observed between cycloplegic and non-cycloplegic refraction among 4-6-year-old children in our previous study [38]. Thirdly, transfer and leaving of some students in this kindergarten may have some impact on the data analysis. For example, the sample size of 4-year-old children in 2013 should be the same as that of 5-year-old children in 2014, but they were different due to the transfer or departure of a number of children. Fourthly, this was not a complete observational study due to the lack of a visit in 2015. In addition, data on time outdoors and bad eyesight habits were collected using questionnaires based on 
self-reports by parents and guardians, which has limited validity. With the development of objective methods of measurement (e.g., FitSight fitness tracker [39] and light meters [29]), data collection will be more credible.

In conclusion, the AL of 4- and 5-year-old children remained relatively stable in Shanghai from 2013 to 2019, except for 2015. Longitudinal studies are needed to confirm the relationship between AL elongation and environmental risk factors.

Acknowledgements This study was supported in part by the Project of Shanghai Science and Technology (grant nos. 17411950200, 17411950203, and 17ZR1404200) and the Project of Shanghai Health and Family Planning Committee (Grant No. 20174Y0177).

\section{Compliance with ethical standards}

Conflict of interest The authors declare that they have no competing interests.

Ethical approval This study was approved by the Ethics Committee of Jinshan Hospital of Fudan University.

Informed consent All procedures conformed to the tenets of the Declaration of Helsinki. Written informed consent was obtained.

Open Access This article is licensed under a Creative Commons Attribution 4.0 International License, which permits use, sharing, adaptation, distribution and reproduction in any medium or format, as long as you give appropriate credit to the original author(s) and the source, provide a link to the Creative Commons licence, and indicate if changes were made. The images or other third party material in this article are included in the article's Creative Commons licence, unless indicated otherwise in a credit line to the material. If material is not included in the article's Creative Commons licence and your intended use is not permitted by statutory regulation or exceeds the permitted use, you will need to obtain permission directly from the copyright holder. To view a copy of this licence, visit http://creativecommons.org/licenses/by/4.0/.

\section{References}

1. Morgan IG, French AN, Ashby RS et al (2018) The epidemics of myopia: aetiology and prevention. Prog Retin Eye Res 62:134-149

2. Morgan IG, Ohno-Matsui K, Saw SM (2012) Myopia. Lancet 379:1739-1748

3. Ohno-Matsui K, Lai TY, Lai CC et al (2016) Updates of pathologic myopia. Prog Retin Eye Res 52:156-187

4. Ruiz-Medrano J, Montero JA, Flores-Moreno I et al (2019) Myopic maculopathy: current status and proposal for a new classification and grading system (ATN). Prog Retin Eye Res 69:80-115

5. Tideman JW, Snabel MC, Tedja MS et al (2016) Association of axial length with risk of uncorrectable visual impairment for Europeans with myopia. JAMA Ophthalmol 134:1355-1363

6. Grossman DC, Curry SJ, Owens DK et al (2017) Vision screening in children aged 6 months to 5 years: US preventive services task force recommendation statement. JAMA 318:836-844

7. Youn DH, Yu YS, Park IW (1990) Intraocular pressure and axial length in children. Korean J Ophthalmol 4:26-29

8. Zhang L, He X, Qu X et al (2018) Refraction and ocular biometry of preschool children in Shanghai. China J Ophthalmol 2018:5205946

9. He XG, Deng JJ, Yin Y et al (2019) Macular choroidal thickness in Chinese preschool children: decrease with axial length but no evident change with age. Int J Ophthalmol 12:1465-1473

10. Bach A, Villegas VM, Gold AS et al (2019) Axial length development in children. Int J Ophthalmol 12:815-819

11. Zhao KK, Yang Y, Wang H et al (2019) Axial length/corneal radius of curvature ratio and refractive development evaluation in 3- to 4-year-old children: the Shanghai Pudong eye study. Int J Ophthalmol 12:1021-1026

12. Han S, Zhang X, Zhao X et al (2019) Stereoacuity and related factors in healthy preschool children: the Nanjing eye study. Ophthalmic Epidemiol 26:336-344

13. Li T, Zhou X, Chen X et al (2019) Refractive error in Chinese preschool children: the Shanghai study. Eye Contact Lens 45:182-187

14. Li T, Jiang B, Zhou X (2019) Axial length elongation in primary school-age children: a 3-year cohort study in Shanghai. BMJ Open 9:e29896

15. Wen G, Tarczy-Hornoch K, McKean-Cowdin R et al (2013) Prevalence of myopia, hyperopia, and astigmatism in nonHispanic white and Asian children: multi-ethnic pediatric eye disease study. Ophthalmology 120:2109-2116

16. Fledelius HC, Christensen AC (1996) Reappraisal of the human ocular growth curve in fetal life, infancy, and early childhood. Br J Ophthalmol 80:918-921

17. Lin LL, Shih YF, Hsiao CK et al (2004) Prevalence of myopia in Taiwanese schoolchildren: 1983 to 2000. Ann Acad Med Singapore 33:27-33

18. Holden BA, Fricke TR, Wilson DA et al (2016) Global prevalence of myopia and high myopia and temporal trends from 2000 through 2050. Ophthalmology 123:1036-1042

19. Jiang WJ, Wu H et al (2017) Corneal diameter and associated parameters in Chinese children: the Shandong children eye study. Clin Exp Ophthalmol 45:112-119

20. Friling R, Weinberger D et al (2004) Keratometry measurements in preterm and full term newborn infants. Br J Ophthalmol 88:8-10

21. Ojaimi E, Robaei D et al (2005) Impact of birth parameters on eye size in a population-based study of 6-year-old Australian children. Am J Ophthalmol 140:535-537

22. Wang D, Huang G et al (2012) Comparison of anterior ocular segment biometry features and related factors among American Caucasians, American Chinese and mainland Chinese. Clin Exp Ophthalmol 40:542-549 
23. Yeter V, Ariturk N et al (2015) Effects of birth weight on anterior segment measurements in full-term children without low birth weight by dual-scheimpflug analyzer. Am J Ophthalmol 160:832-840.e1

24. Zhang Y, Wang $\mathrm{H}$ et al (2019) The association between urbanization and child height: a multilevel study in China. BMC Public Health 19:569

25. Okubo H, Murakami K et al (2018) The relationship of eating rate and degree of chewing to body weight status among preschool children in Japan: a nationwide crosssectional study. Nutrients 11:64

26. Russell CG, Haszard JJ et al (2018) Parental feeding practices associated with children's eating and weight: what are parents of toddlers and preschool children doing? Appetite 128:120-128

27. He M, Xiang F, Zeng Y et al (2015) Effect of time spent outdoors at school on the development of myopia among children in China: a randomized clinical trial. JAMA 314:1142-1148

28. Li SM, Li H, Li SY et al (2015) Time outdoors and myopia progression over 2 years in Chinese children: the anyang childhood eye study. Invest Ophthalmol Vis Sci 56:4734-4740

29. Wu PC, Chen CT, Lin KK et al (2018) Myopia prevention and outdoor light intensity in a school-based cluster randomized trial. Ophthalmology 125:1239-1250

30. Huang PC, Hsiao YC, Tsai CY et al (2019) Protective behaviours of near work and time outdoors in myopia prevalence and progression in myopic children: a 2-year prospective population study. $\mathrm{Br} \mathrm{J}$ Ophthalmol 104:956-961
31. Wu PC, Tsai CL, Wu HL et al (2013) Outdoor activity during class recess reduces myopia onset and progression in school children. Ophthalmology 120:1080-1085

32. Deng L, Pang Y (2019) Effect of outdoor activities in myopia control: meta-analysis of clinical studies. Optom Vis Sci 96:276-282

33. Lingham G, Mackey DA, Lucas R et al (2019) How does spending time outdoors protect against myopia? A review. Br J Ophthalmol 104:593-599

34. Ku PW, Steptoe A, Lai YJ et al (2019) The associations between near visual activity and incident myopia in children: a nationwide 4-year follow-up study. Ophthalmology 126:214-220

35. Saw SM, Nieto FJ, Katz J et al (2000) Factors related to the progression of myopia in Singaporean children. Optom Vis Sci 77:549-554

36. Ding X, Hu Y, Guo X et al (2018) Possible causes of discordance in refraction in monozygotic twins: nearwork, time outdoors and stochastic variation. Invest Ophthalmol Vis Sci 59:5349-5354

37. Morgan IG, French AN, Rose KA (2018) Intense schooling linked to myopia. BMJ 361:k2248

38. Li T, Zhou X, Zhu J et al (2019) Effect of cycloplegia on the measurement of refractive error in Chinese children. Clin Exp Optom 102:160-165

39. Verkicharla PK, Ramamurthy D, Nguyen QD et al (2017) Development of the fitsight fitness tracker to increase time outdoors to prevent myopia. Transl Vis Sci Technol 6:20

Publisher's Note Springer Nature remains neutral with regard to jurisdictional claims in published maps and institutional affiliations. 